\title{
Associations of smoking behavior with lifestyle and mental health among Japanese dental students
}

Yuko Fujita* (1) and Kenshi Maki

\begin{abstract}
Background: Smoking is a major risk factor for cancer and cardiovascular disease. However, mental stress leads to smoking in dental students. We believe that dentists, as health professionals, should set an example for the public. Therefore, this study determined the prevalence of and factors associated with regular smoking among Japanese dental students. We also surveyed their attitudes regarding smoking cessation and how to counsel smokers about quitting.
\end{abstract}

Methods: We collected demographic and behavioral data from 453 students at Kyushu Dental University, and evaluated their mental health with the 12-item General Health Questionnaire (GHQ 12). We also asked them nine questions related to their intentions to counsel smokers about quitting. A multivariate binary logistic regression analysis was used to identify factors associated with smoking.

Results: Fifty-two (11.5\%) of the dental students smoked. Univariate analyses indicated that male gender, higher academic year, greater number of times eating out per day, alcohol consumption, prevalence of skipping breakfast, poor health, and poor sleep habits were significantly associated with regular smoking. Regular smokers were less likely to have GHQ 12 scores $\geq 4$. On multivariate analysis, male gender $(O R=5.449,95 \% \mathrm{Cl}=1.851-16.040)$, sixth year students $(\mathrm{OR}=21.971,95 \% \mathrm{Cl}=1.686-286.290)$, eating out two or more times a day $(\mathrm{OR}=2.492,95 \% \mathrm{Cl}$ $=1.165-5.331)$, drinking alcohol three or more times per week $(\mathrm{OR}=9.484,95 \% \mathrm{Cl}=3.335-26.970)$, and $\mathrm{GHQ}$ 12 score $\geq 4(\mathrm{OR}=0.339,95 \% \mathrm{Cl}=0.136-0.845)$ were significantly associated with regular smoking. Overall, $50.1 \%$ of the non-smokers and $71.2 \%$ of the regular smokers responded that patients' chances of quitting smoking are not increased when a dentist advises them to quit.

Conclusions: Regular smoking was strongly associated with male gender, higher academic year, alcohol consumption, and higher frequency of eating out per day. Mental health status among regular smokers was better than that among non-current smokers. Furthermore, we found that more than half of dental students have inadequate attitudes to advise their patients to quit smoking. It is necessary to develop educational programs regarding smoking for dental students.

Keywords: Dental students, Smoking behavior, Life style, Mental health

\footnotetext{
* Correspondence: y-fujita@kyu-dent.ac.jp

All in the Division of Developmental Stomatognathic Function Science,

Department of Health Promotion, Kyushu Dental University, 2-6-1 Manazuru,

Kokurakita-ku, Kitakyushu 803-8580, Japan
}

(c) The Author(s). 2018 Open Access This article is distributed under the terms of the Creative Commons Attribution 4.0 International License (http://creativecommons.org/licenses/by/4.0/), which permits unrestricted use, distribution, and reproduction in any medium, provided you give appropriate credit to the original author(s) and the source, provide a link to the Creative Commons license, and indicate if changes were made. The Creative Commons Public Domain Dedication waiver (http://creativecommons.org/publicdomain/zero/1.0/) applies to the data made available in this article, unless otherwise stated. 


\section{Background}

Smoking is a major risk factor for cancer [1-3] and cardiovascular disease [4], and both smoking and drinking alcohol are health hazards. A recent World Health Organization study of the global tobacco epidemic showed that $21 \%$ of adults globally, or 950 million men and 177 million women, were current smokers in 2013. Smoking prevalence is highest in high-income countries, with 25\% of adults being current smokers in 2013 [5]. In Japan, the National Health and Nutrition Survey showed that the prevalence of current cigarette smoking among Japanese adult males decreased gradually from 39.9\% in 2006 to $30.2 \%$ in 2016 [6]. In the USA, cigarette smoking among adult males declined from $23.9 \%$ in 2005 to $18.8 \%$ in 2014 [7]. These data suggest that the prevalence of smoking in Japanese men is high among developed nations.

The reported prevalence of current smoking among Japanese male dentists was $27.1 \%$ in 2008 [8], which is significantly higher than the rate among Japanese male physicians (15.0\%) [9]. It has been reported that the smoking rate among physicians is declining in Japan [10], while changes in prevalence of smoking among dentists are still unclear. In addition, no information is available regarding the attitudes of Japanese dentists toward smoking cessation in recent years. Several studies have shown that many dental students suffer from psychological stress due to their many examinations and personal problems $[11,12]$. A recent study showed that stress from the heavy course load was the main reason that dental students initiated smoking [13]. A few studies have suggested that the nicotine contained in tobacco has antidepressant-like effects in depressed patients [14] and small animal models [15]. Therefore, we hypothesized that students with mental health disturbances depend on the use of tobacco to improve their condition. However, dentists have a responsibility to provide public awareness of smoking prevention and cessation, and to facilitate improvements in public health. We also believe that dentists as health professionals should serve as examples to the public. However, there is no information regarding the associations between smoking behavior and lifestyle and mental health or attitudes regarding smoking intervention among Japanese dental students.

This study determined the prevalence of and factors associated with regular smoking among Japanese dental students and surveyed their attitudes toward smoking cessation and counseling smokers about quitting.

\section{Methods}

This study was approved by the Human Investigations Committee of Kyushu Dental University (14-35) and all subjects provided written informed consent before participating.
A survey was completed by 453 dental students (200 women, 253 men) in six dental classes at Kyushu Dental University in April 2015. These students entered dental university after graduating from high school in April 2015. The first and second years of this university program provide general and preclinical education. The third and fourth years are also preclinical, but at the end of fourth year, students can take common achievement tests, including computer-based testing and the Objective Structured Clinical Examination. In the fifth and sixth years, students undertake clinical clerkship at the university hospital.

We planned a study with 40 regular smokers and 413 non-current smokers. Prior data indicated that $63 \%$ of non-current smokers were male [16]. With a true within-stratum odds ratio for regular smoking in males relative to females of 3.5 , we would be able to reject the null hypothesis that this odds ratio equals 1 with probability (power) 0.882 . The type I error probability associated with this test of the null hypothesis was 0.05 . We used an uncorrected chi-squared statistic to evaluate this null hypothesis.

The survey solicited the following information: demographic characteristics (gender, age, and academic year), body mass index, current and past smoking habits, residence, eating habits, health status, physical activity, participation in club activities, sleep, alcohol use, participation in smoking cessation education, and smokers in respondents' families. Mental health was assessed using the 12-item General Health Questionnaire (GHQ 12) Japanese version. The validity and reliability of GHQ12 have been previously confirmed [17, 18]. GHQ 12 responses were scored as 0 or 1 , and the total score ranged from 0 to 12 points [19]. We used the cutoff of 4 points arrived at by Guthrie et al. [20] in their investigation of stress and burnout in medical students. High scores indicate low mental health status.

The participants were classified as non-current smokers and regular smokers. Regular smokers were those who answered "daily" or "sometimes" to the question on current smoking status in the last month; all others were defined as non-current smokers.

We evaluated whether the participants had professional responsibilities associated with smoking intervention using nine questions on professional responsibility adapted from a study of Japanese medical students [16]. One point was added when a suitable response was given to each question, and the sum of suitable responses was the individual professionalism score. All questionnaires were applied in Japanese. Factor analyses were applied to assess the validity of the questionnaire on professional responsibility [21]. For exploratory factor analysis, principal factor analysis with Varimax rotation was performed. Kaiser's criterion (i.e., eigenvalues > 1.0) 
and a visual examination of scree plots were used to determine the number of components to retain [22-24]. Following principal factor analysis, confirmatory factor analysis was performed to explore the valid factor structure. The goodness-of-fit index (GFI), adjusted GFI (AGFI), comparative fit index (CFI), and root-meansquare error of approximation (RMSEA) were used as indices of conformity. In general, GFI, AGFI, and CFI values of $\geq 0.90$ indicate good fits $[25,26]$. In addition, the RMSEA was interpreted as follows: good, $\leq 0.05$; and acceptable, $\leq 0.08$ [27]. Furthermore, Cronbach's alpha coefficient was used as an index of internal consistency of the questionnaire, with $\alpha \geq 0.7$ accepted as evidence of good internal consistency [28].

\section{Statistical methods}

When appropriate, the chi-squared test or Fisher's exact test was used to compare categorical variables between non-smokers and regular smokers. The independent $t$-test was used to compare the means of continuous variables. A multivariate binary logistic regression analysis was used to identify factors associated with smoking. $P$-values $<0.05$ indicated statistical significance. In the binary logistic regression analysis, current smoking status was considered to be the dependent variable, and independent variables that were significant in the univariate analyses were included. Categorical variables were coded appropriately before they were entered into the model. The adjusted odds ratios (ORs) for smoking and their $95 \%$ confidence intervals (CIs) were calculated. All statistical analyses were performed using SPSS for Windows ver. 23.0 (IBM Japan, Tokyo, Japan).

\section{Results}

As the results for validity and reliability of the questionnaire on professional responsibility, from Kaiser's criterion, three factors had eigenvalues $>1$, which together accounted for $55.2 \%$ of the variance in the total scores. The results of confirmatory factor analysis showed goodness-of-fit of the three-factor structure models in the questionnaires as follows: GFI= 0.947, AGFI $=0.910$, CFI $=0.954$, and RMSEA $=0.062$. With regard to internal consistency of the questionnaire, Cronbach's alpha coefficients of the scale and its three subscales were $0.701-0.853$.

Table 1 summarizes the demographic characteristics of the 453 participants (200 women, 253 men) who completed the survey. The mean response rate of all students was $78.6 \%$.

Table 2 shows the results of the assessment of smoking habits according to demographics. Overall, 11.5\% ( $n=$ 52) of respondents were regular smokers. The prevalence of regular smokers was significantly higher among men than among women $(p=0.000)$. Age and academic
Table 1 Participant characteristics

\begin{tabular}{llll}
\hline Variable & Female (\%) & Male (\%) & Total (\%) \\
\hline $\begin{array}{l}\text { Participants } \\
\text { Age (years) }\end{array}$ & $200(44.2)$ & $253(55.8)$ & $453(100)$ \\
mean \pm SD & $21.69 \pm 2.32$ & $22.38 \pm 2.58$ & $22.07 \pm 2.49$ \\
$18-20$ & $68(34.0)$ & $67(26.5)$ & $135(29.8)$ \\
$20-22$ & $84(42.0)$ & $110(43.5)$ & $194(42.8)$ \\
$23-26$ & $39(19.5)$ & $54(21.3)$ & $93(20.5)$ \\
$\geq 27$ & $9(4.5)$ & $22(8.7)$ & $31(6.8)$ \\
Academic year & & & Responses (\%) \\
1st & $34(17.0)$ & $42(16.6)$ & $76 / 97(78.4)$ \\
2nd & $40(20.0)$ & $46(18.2)$ & $86 / 103(83.5)$ \\
3rd & $35(17.5)$ & $34(13.4)$ & $69 / 97(71.1)$ \\
4th & $39(20.5)$ & $37(15.0)$ & $76 / 96(79.2)$ \\
5th & $22(11.0)$ & $46(18.2)$ & $68 / 87(78.2)$ \\
6th & $30(15.0)$ & $48(19.0)$ & $78 / 96(81.3)$ \\
Ever smoked & & & \\
Never & $183(91.5)$ & $163(64.4)$ & $346(76.4)$ \\
Yes & $17(8.5)$ & $90(35.6)$ & $107(23.6)$ \\
\hline SD stanca) & &
\end{tabular}

$S D$ standard deviation

year were significantly higher among regular smokers than among non-current smokers (both $p=0.000$ ).

Table 3 summarizes the assessment of smoking habits according to behavioral variables and mental health. Smokers were more likely to skip breakfast twice or more a week, eat out once or more a week, have poor health and sleep, and drink alcohol $(p=0.001, p=0.000$, $p=0.014, p=0.040$, and $p=0.000$, respectively). In contrast, regular smokers were less likely to have GHQ 12 scores $\geq 4$ and to attend smoking cessation education ( $p$ $=0.017$ and $p=0.035$, respectively). The mean GHQ 12 score was significantly lower among regular smokers that among non-current smokers $(p=0.003)$ and in men than in women $(p=0.023)$.

Table 4 summarizes the assessment of smoking habits according to the family history of smoking. Smoking was associated significantly with fathers' smoking habits $(p=0.010)$.

Table 5 summarizes the professional responsibility results. Responses to five questions differed significantly between regular smokers and non-current smokers. The mean professionalism score was significantly lower among regular smokers than among non-current smokers $(p<$ 0.001 ). Overall, $50.1 \%$ of the non-current smokers and $71.2 \%$ of the regular smokers responded that patients' chances of quitting smoking were not increased if a dentist advised them to quit.

Table 6 shows the results of the logistic regression analysis. The multivariate analysis revealed that male gender $(\mathrm{OR}=5.449, p=0.002,95 \% \mathrm{CI}=1.851-16.040)$; 
Table 2 Assessment of smoking habits according to demographic characteristics

\begin{tabular}{|c|c|c|c|c|}
\hline & Non-current smokers (\%) & Regular smokers (\%) & $x^{2}$ & $p$-value \\
\hline Participants $(n=453)$ & $401(88.5)$ & $52(11.5)$ & & \\
\hline \multicolumn{5}{|l|}{ Gender } \\
\hline Female & $195(48.6)$ & $5(9.6)$ & & \\
\hline \multirow[t]{2}{*}{ Male } & $206(51.4)$ & $47(90.4)$ & & \\
\hline & & & 28.413 & $0.000^{\mathrm{a}}$ \\
\hline \multicolumn{5}{|l|}{ Age (years) } \\
\hline mean $\pm S D$ & $21.88 \pm 2.44$ & $23.54 \pm 2.39$ & - & $0.000^{\mathrm{b}}$ \\
\hline $18-20$ & $130(32.4)$ & $5(9.6)$ & & \\
\hline $21-23$ & $168(41.9)$ & $26(50.0)$ & & \\
\hline $24-26$ & $81(20.2)$ & $12(23.1)$ & & \\
\hline \multirow[t]{2}{*}{$\geq 27$} & $22(5.5)$ & $9(17.3)$ & & \\
\hline & & & 18.324 & $0.000^{\mathrm{a}}$ \\
\hline \multicolumn{5}{|l|}{ Academic year } \\
\hline 1 st & $75(18.7)$ & $1(1.9)$ & & \\
\hline 2nd & $80(20.0)$ & $6(11.5)$ & & \\
\hline $3 r d$ & $62(15.5)$ & $7(13.5)$ & & \\
\hline 4th & $69(17.2)$ & $7(13.5)$ & & \\
\hline 5th & $53(13.2)$ & $15(28.8)$ & & \\
\hline \multirow[t]{2}{*}{ 6th } & $62(15.5)$ & $16(30.8)$ & & \\
\hline & & & 23.702 & $0.000^{\mathrm{a}}$ \\
\hline \multicolumn{5}{|c|}{ Body Mass Index $\left(\mathrm{kg} / \mathrm{m}^{2}\right)$} \\
\hline mean $\pm S D$ & $20.85 \pm 3.92$ & $21.91 \pm 2.55$ & - & $0.070^{\mathrm{b}}$ \\
\hline$<18.5$ & $43(14.7)$ & $3(6.1)$ & & \\
\hline $18.5-24.9$ & $216(73.7)$ & $41(83.7)$ & & \\
\hline \multirow[t]{2}{*}{$\geq 25.0$} & $34(11.6)$ & $5(10.2)$ & & \\
\hline & & & 2.909 & $0.234^{a}$ \\
\hline
\end{tabular}

$S D$ standard deviation. ${ }^{a}$ Chi-square test, ${ }^{b} t$ test

higher academic year, including years $4(\mathrm{OR}=14.923, p$ $=0.043,95 \% \mathrm{CI}=1.094-203.531), 5(\mathrm{OR}=21.935, p=$ $0.017,95 \% \mathrm{CI}=1.746-275.497)$, and $6(\mathrm{OR}=21.971, p=$ 0.018, 95\% CI $=1.686-286.290)$; eating out twice or more a day $(\mathrm{OR}=2.492, \quad p=0.019, \quad 95 \% \quad \mathrm{CI}=1.165-$ 5.331); and drinking alcohol less than three times a week $(\mathrm{OR}=3.336, p=0.017,95 \% \mathrm{CI}=1.241-8.970)$ or three times or more a week $(\mathrm{OR}=9.484, p=0.000,95 \% \mathrm{CI}$ $=3.335-26.970$ ) were associated with higher odds of regular smoking. In contrast, GHQ 12 score $\geq 4$ was associated with lower odds of regular smoking ( $\mathrm{OR}=$ $0.339, p=0.020,95 \% \mathrm{CI}=0.136-0.845)$. For every point increase in the professionalism score, the odds of smoking decreased by a factor of $0.719(p=0.000$, 95\% CI $=0.608-0.850)$.

\section{Discussion}

This study showed that the overall prevalence of regular smoking among the respondents in our study was lower than reported for dental students in other countries [13,
29-35]. Consistent with previous studies, regular smoking was more prevalent among men than among women [13, 29-35]. Previous studies have indicated that the harmful effects of smoking during pregnancy on maternal and fetal health are well recognized among women in Japan and the United States [36, 37]. It is likely that female students have a better understanding and care more about pregnancy and childbirth as well as their own health than male students. Several studies have indicated that family influence is a major risk factor for and predictor of the initiation of smoking $[13,16]$, although one study showed that a family history of smoking was not associated with smoking. We found that 50 (96.2\%) regular smokers did not live with their families. A previous study indicated that cigarette smoking in college students is often a social activity associated with facilitation of social interactions, to avoid feeling alone, and to behave as a member of a group [38]. Students may have become regular smokers because of the lack of family members who cautioned against smoking, and 
Table 3 Assessment of smoking habits according to behavioral variables and mental health

Non-current smokers (\%) Regular smokers

$x^{2} \quad p$-value

(\%)

Residence

With family

$53(13.2)$

$2(3.8)$

Alone

$348(86.8)$

$50(96.2)$

3.789

$0.052^{\mathrm{a}}$

Skipping breakfast

Less than twice a week

$233(58.1)$

$17(32.7)$

Twice or more a week

$168(41.9)$

$35(67.3)$

12.02

$0.001^{\mathrm{a}}$

Eating between meals

Less than once a week

$252(62.8)$

$33(63.5)$

Once or more a week

$149(37.2)$

19 (36.5)

Eating out

Less than twice a day

$265(66.1)$

19 (36.5)

Twice or more a day

$136(33.9)$

$33(63.5)$

17.181

$0.000^{\mathrm{a}}$

Health status

Good

$351(87.5)$

39 (75.0)

Poor

$50(12.5)$

$13(25.0)$

Physical activity,

30 min or more a day

Less than 30 min a day

$216(53.9)$

$185(46.1)$

$333(83.0)$

$68(17.0)$

307 (76.6)

$94(23.4)$

$241(60.1)$

$160(39.9)$

$\geq 6 \mathrm{~h}$

Alcohol drinking

Never

Less than three times a week

Three times or more a week

mean \pm SD
$209(52.1)$

$143(35.7)$

$49(14.2)$

\section{GHQ 12 score}$$
\text { mean } \pm S D
$$

$30(57.7)$

$22(42.3)$

0.272

$0.602^{a}$

44 (84.6)

$8(15.4)$

0.082

$0.775^{\mathrm{a}}$

$33(63.5)$

$19(36.5)$

4.217

$0.040^{\mathrm{a}}$

$25(48.1)$

27 (51.9)

2.745

$0.098^{\mathrm{a}}$

$8(15.4)$

$21(40.4)$

$23(44.2)$ 
Table 3 Assessment of smoking habits according to behavioral variables and mental health (Continued)

\begin{tabular}{|c|c|c|c|c|}
\hline & Non-current smokers (\%) & $\begin{array}{l}\text { Regular smokers } \\
(\%)\end{array}$ & $x^{2}$ & $p$-value \\
\hline Female $(n=200)$ & $3.67 \pm 2.94$ & $3.00 \pm 4.63$ & - & $0.621^{c}$ \\
\hline Male $(n=253)$ & $2.94 \pm 2.72$ & $2.11 \pm 2.07$ & - & $0.023^{c}$ \\
\hline Total $(n=453)$ & $3.30 \pm 2.86$ & $2.19 \pm 2.35$ & - & $0.003^{c}$ \\
\hline$<4$ & $240(59.9)$ & $40(76.9)$ & & \\
\hline \multirow[t]{2}{*}{$\geq 4$} & $161(40.1)$ & $12(23.1)$ & & \\
\hline & & & 5.684 & $0.017^{a}$ \\
\hline \multicolumn{5}{|c|}{ Received training in smoking cessation } \\
\hline Yes & $389(97.0)$ & $47(90.4)$ & & \\
\hline \multirow[t]{2}{*}{ No } & $12(3.0)$ & $5(9.6)$ & & \\
\hline & & & 5.59 & $0.035^{\mathrm{b}}$ \\
\hline
\end{tabular}

$\overline{G H Q}$ General Health Questionnaire (high scores indicate low mental health status), SD standard deviation. ${ }^{\text {a }}$ Chi-square test, ${ }^{b}$ Fisher's exact test, ${ }^{c} t$ test

instead were influenced by their friends who were smokers. Many studies have shown that alcohol consumption is significantly associated with cigarette smoking $[16,39,40]$, which was consistent with our findings. Alcohol is an effective anxiolytic in humans and animals $[41,42]$; therefore, the desire to drink may be motivated by the wish to alleviate stress [43]. Another study indicated that drinkers had many other drinkers in their social network and the frequency of individual drinking was related to the frequency of drinking by others [44]. This trend was very similar to that seen in smokers [45]. These findings are correlated with the observation that eating out more times per day is associated with higher odds of being a regular smoker. Drinking and smoking may play roles in stress relief as well as in building and maintaining interpersonal relationships.

Recent studies have revealed very strong associations between cigarette smoking and mental health variables in college students in the United States [46, 47]. In contrast, we found that the mean GHQ 12 score was significantly lower among regular smokers than among non-current smokers, suggesting that the mental health state was lower among non-current smokers than among regular smokers. In a recent study, the mean GHQ 12 scores for female and male participants were 3.82 and 3.00, respectively, and significant gender-related differences were observed among Japanese medical students regardless of smoking habit [48]. Consistent with

Table 4 Assessment of smoking habits according to family members' smoking

\begin{tabular}{|c|c|c|c|c|}
\hline & Non-current smokers (\%) & Regular smokers (\%) & $x^{2}$ & $p$-value \\
\hline \multicolumn{5}{|l|}{ Father } \\
\hline Non-smoker or no father & $330(82.3)$ & $35(67.3)$ & & \\
\hline \multirow[t]{2}{*}{ Regular smoker } & $71(17.7)$ & $17(32.7)$ & & \\
\hline & & & 6.605 & $0.010^{\mathrm{a}}$ \\
\hline \multicolumn{5}{|l|}{ Mother } \\
\hline Non-smoker or no mother & $383(95.5)$ & $47(90.4)$ & & \\
\hline \multirow[t]{2}{*}{ Regular smoker } & $18(4.5)$ & $5(9.6)$ & & \\
\hline & & & 2.51 & $0.167^{b}$ \\
\hline \multicolumn{5}{|l|}{ Brother } \\
\hline Non-smoker or no brother & $371(92.5)$ & $45(86.5)$ & & \\
\hline \multirow[t]{2}{*}{ Regular smoker } & $30(7.5)$ & $7(13.5)$ & & \\
\hline & & & 2.195 & $0.172^{b}$ \\
\hline \multicolumn{5}{|l|}{ Sister } \\
\hline Non-smoker or no sister & $396(98.8)$ & $51(98.1)$ & & \\
\hline \multirow[t]{2}{*}{ Regular smoker } & $5(1.2)$ & $1(1.9)$ & & \\
\hline & & & 0.161 & $0.521^{\mathrm{b}}$ \\
\hline
\end{tabular}

${ }^{a}$ Chi-square test, ${ }^{\text {b}}$ Fisher's exact test 
Table 5 Responses of dental students to smoking intervention statements

\begin{tabular}{llll}
\hline & Non-current smokers (\%) & Regular smokers (\%) & $x^{2}$ \\
\hline $\begin{array}{l}\text { 1. Do you think that dental students should not smoke? } \\
\text { Yes (score 1) }\end{array}$ & $333(83.0)$ & $31(59.6)$ & $18(34.6)$ \\
No (score 0) & $38(9.5)$ & $3(5.8)$ & \\
No opinion (score 0) & $30(7.5)$ & & 26.861 \\
& & $2(42.3)$ \\
2. What is your view on smoking by patients? & $245(61.1)$ & $8.000^{\text {a }}$ \\
They should not smoke. (score 1) & $38(9.5)$ & $20(38.5)$ \\
There is no problem with them smoking. (score 0) & $109(27.2)$ & $2(3.8)$ \\
Patients may smoke at their discretion. (score 0) & $9(2.2)$ &
\end{tabular}

3. We should serve as role models for their patients and the public.

$\begin{array}{lll}\text { Yes (score 1) } & 369(92.0) & 44(84.6) \\ \text { No (score 0) } & 32(8.0) & 8(15.4)\end{array}$

4. Dentists should master the ability to be non-smokers.
Yes (score 1)
$340(84.8)$
$31(59.6)$
No (score 0)
$61(15.2)$
$21(40.4)$

5. Dentists should be examples to patients with regard to cessation of smoking.
Yes (score 1)
$329(82.0)$
$32(61.5)$
No (score 0)
$72(18.0)$
$20(38.5)$

6. Dentists should advise patients not to smoke.

Yes (score 1)

$329(82.0)$

No (score 0)

$72(18.0)$

7. Dentists should provide patients with information related to non-smoking.
Yes (score 1)
376 (93.8)
$45(86.5)$
No (score 0)
$25(6.2)$
$7(13.5)$

3.662

$0.077^{b}$

8. Are a patient's chances of quitting smoking increased if a dentist advices him/her to quit?
Yes (score 1)
200 (49.9)
$15(28.8)$
No (score 0)
$201(50.1)$
$37(71.2)$

8.163

$0.004^{\mathrm{a}}$

9. Dentists are free to smoke as people in other occupations.
Yes (score 0)
128 (31.9)
$26(50.0)$
No (score 1)
$273(68.1)$
$26(50.0)$

$6.706 \quad 0.010^{\mathrm{a}}$

Professionalism score (0-9 points)

$\frac{\text { mean } \pm S D}{S D \text { standard deviation. }{ }^{a} \text { Chi-square test, }{ }^{b} \text { Fisher's exact test. }{ }^{c} t \text { test }}$

$6.96 \pm 1.99$

$5.64 \pm 2.59$

$0.001^{c}$ 
Table 6 Multiple logistic regression analysis for predictors associated with regular smoking

\begin{tabular}{|c|c|c|c|c|}
\hline Independent variables & Category & $\begin{array}{l}\text { Adjusted Odds ratio } \\
(95 \% \mathrm{Cl})\end{array}$ & $p$-value & Score Assigned \\
\hline \multirow[t]{2}{*}{ Gender } & Female & 1 & - & 0 \\
\hline & Male & $5.449(1.851-16.040)$ & 0.002 & 1 \\
\hline \multirow[t]{4}{*}{ Age (years) } & $18-20$ & 1 & - & 0 \\
\hline & $21-23$ & $0.735(0.161-3.362)$ & 0.691 & 1 \\
\hline & $24-26$ & $0.481(0.088-2.626)$ & 0.398 & 2 \\
\hline & $27 \leq$ & $2.123(0.396-11.382)$ & 0.380 & 3 \\
\hline \multirow[t]{6}{*}{ Academic year } & $1 s t$ & 1 & - & 0 \\
\hline & 2nd & $5.002(0.487-51.376)$ & 0.176 & 1 \\
\hline & $3 r d$ & $8.478(0.716-100.318)$ & 0.090 & 2 \\
\hline & 4th & $14.923(1.094-203.531)$ & 0.043 & 3 \\
\hline & 5th & $21.935(1.746-275.497)$ & 0.017 & 4 \\
\hline & 6th & $21.971(1.686-286.290)$ & 0.018 & 5 \\
\hline \multirow[t]{2}{*}{ Skipping breakfast } & Less than twice a week & 1 & - & 0 \\
\hline & Twice or more a week & $1.806(0.848-3.846)$ & 0.126 & 1 \\
\hline \multirow[t]{2}{*}{ Eating out } & Less than twice a day & 1 & - & 0 \\
\hline & Twice or more a day & $2.492(1.165-5.331)$ & 0.019 & 1 \\
\hline \multirow[t]{2}{*}{ Health status } & Good & 1 & - & 0 \\
\hline & Poor & $2.248(0.855-5.911)$ & 0.101 & 1 \\
\hline \multirow[t]{2}{*}{ Sleeping status } & Good & 1 & - & 0 \\
\hline & Poor & $1.232(0.527-2.883)$ & 0.630 & 1 \\
\hline \multirow[t]{3}{*}{ Alcohol drinking } & Never & 1 & - & 0 \\
\hline & Less than three times a week & $3.336(1.241-8.970)$ & 0.017 & 1 \\
\hline & Three times or more a week & $9.484(3.335-26.970)$ & 0.000 & 2 \\
\hline \multirow[t]{2}{*}{ GHQ 12 score } & $<4$ & 1 & - & 0 \\
\hline & $\geq 4$ & $0.339(0.136-0.845)$ & 0.020 & 1 \\
\hline \multirow[t]{2}{*}{ Received training in smoking cessation } & Yes & 1 & - & 0 \\
\hline & No & $2.985(0.640-13.915)$ & 0.164 & 1 \\
\hline \multirow[t]{2}{*}{ Father's smoking } & Non-smoker or no father & 1 & - & 0 \\
\hline & Regular smoker & $1.812(0.757-4.340)$ & 0.182 & 1 \\
\hline Professionalism score (per 1 point increase) & & $0.719(0.608-0.850)$ & 0.000 & - \\
\hline
\end{tabular}

-2 Log likelihood $=201.673$

Hosmer and Lemeshow test: $X^{2}=3.596, p=0.892$

Cox-Snell $R^{2}=0.235$

Nagelkerke $R^{2}=0.461$

$\mathrm{Cl}$ confidence interval, GHQ General Health Questionnaire (high score indicate low mental health ststus)

these findings, mean GHQ 12 scores were higher in women than in men in this study. As $90.4 \%$ of regular smokers were men, it is natural that the mean GHQ scores of all regular smokers were close to those of regular male smokers. However, the mean GHQ scores among regular smokers were lower than those among non-current smokers, especially in men. Therefore, smoking appeared to have some impact on the decline in GHQ score. Another study suggested that nicotine critically regulates brain areas that are involved in the inhibition of negative emotions, such as anger [49], which may be one of reason for the lower scores among regular smokers than non-current smokers.

Univariate analyses showed that the prevalences of skipping breakfast, poor health status, and poor sleep habits were significantly associated with regular smoking, although they were not statistically significant on multivariate analysis. These findings suggested that regular smokers tended to have unhealthy lifestyles, including nocturnal habits. Generally, there are large variations in the preferred timing of sleep and activity, and this temporal directionality of activities of individuals is 
referred to as the chronotype [50]. In 1976, Horne and Ostberg [50] developed a questionnaire to classify individuals based on their preferences for sleep timing and daily performance, and classified chronotype into three types: evening type, morning type, and intermediate type. Evening type is associated with peak performance toward the end of the day. Unfortunately, in modern society sleep timing, especially on work days, is influenced by social norms, a phenomenon known as "social jet lag" [51]. Obviously, this is disadvantageous in evening types. Many studies have indicated lifestyle-related health problems in evening type people. Evening types were reported to skip breakfast more often than morning types [52]. Evening types experienced anxiety and negative moods, tended to have lower self-esteem, performed worse in school, and were suggested to be more susceptible to stress [53]. Furthermore, evening types with reduced sleep on weekdays compared to weekends showed higher incidences of depressive moods [54] and engaged in more negative health behaviors than morning types [55]. In this study, we did not diagnose the chronotypes of the students, although the behavioral features associated with regular smokers on univariate analyses were consistent with evening types. Only mental health status in regular smokers was inconsistent with the characteristics of evening types. However, our results are reasonable if students with poor mental health status due to social jet lag used smoking to improve their condition. Students who are aware that they have a predisposition for the evening type chronotype, especially men, must manage their health to a greater degree than others because they have the potential to become regular smokers.

We asked the students nine questions associated with professional responsibility, including their intention to counsel smokers about quitting, and found significantly lower scores among regular smokers compared with non-current smokers. These findings suggest that regular smokers are less conscious health professionals. In addition, $50.1 \%$ of the non-current smokers and $71.2 \%$ of the regular smokers responded that patients' chances of quitting smoking are not increased if a dentist advises them to quit. The Global Health Professions Student Survey of 28,420 medical, dental, nursing, and pharmacy students from eight countries showed that dental students had significantly lower odds of being taught to provide educational materials to support smoking cessation for patients who want to quit smoking, compared with medical, nursing, and pharmacy students [56]. We also found that more than half of the students had an inadequate attitude toward smoking cessation by their patients. Prakash et al. [57] demonstrated that dentists can play an important role in primary prevention of adverse health effects by promoting the cessation of tobacco use among their patients.
In the clinical training of dental students, information about tobacco cessation treatment is provided by various educational methods, such as didactic lectures, web-based learning, and interactive CD-ROM programs. In addition, Objective Structured Clinical Examinations as an assessment method in clinical training was provided $[58,59]$. Singleton et al. [60] suggested that a method that combined lectures with practice sessions with standardized patients increased participants' subjective norms, perceived skills, and intentions to provide tobacco cessation treatment more than lectures alone. Therefore, it is necessary to apply more practical learning and assessment after passive learning during training of students to support smoking cessation for their patients.

We found that Japanese dental students have inadequate attitudes and skills to advise their patients to quit smoking, although most students held positive attitudes toward smoking prevention and cessation. The development of educational programs including tobacco cessation treatment for dental students in Japan is necessary.

\section{Conclusions}

Regular smoking was strongly associated with male gender, higher academic year, consumption of alcohol, and eating out more often. Mental health status among regular smokers was better than among non-current smokers. Behavioral features of regular smokers were consistent with the characteristics of evening types. Students who are aware that they have predisposition for the evening type chronotype, especially among men, must manage their health much more carefully than those with other chronotypes. Furthermore, we found that more than half of the dental students had inadequate attitudes and skills to advise their patients to quit smoking. Consequently, the development of educational programs for dental students in Japan is necessary.

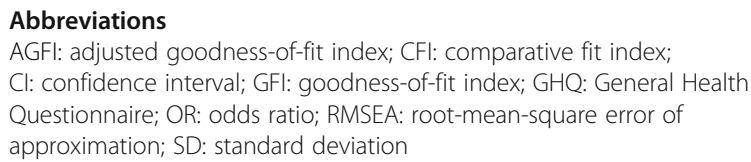

\section{Acknowledgements}

We would like to thank Yuki Arita and Kentaro Okamoto who assisted data acquisition.

\section{Funding \\ No funding.}

\section{Availability of data and materials}

The datasets during and /or analyzed during the current study available from the corresponding author on reasonable request.

\section{Authors' contributions}

YF formulated the study design, participated in data acquisition, analysis and drafted the whole manuscript. KM supervised the data analysis and interpretation, edited and gave the final approval of the manuscript. All authors read and approved the final manuscript. 


\section{Ethics approval and consent to participate}

This study was approved by the Human Investigations Committee of Kyushu Dental University (14-35) and all subjects provided written informed consent prior to participation.

\section{Consent for publication}

Written informed consent was obtained from study participants for participation in the study and for publication of this research.

\section{Competing interests}

The authors declare that have no competing interests.

\section{Publisher's Note}

Springer Nature remains neutral with regard to jurisdictional claims in published maps and institutional affiliations.

\section{Received: 8 February 2018 Accepted: 31 October 2018 Published online: 16 November 2018}

\section{References}

1. Boffetta P, Jayaprakash V, Yang P, Asomaning K, Muscat JE, Schwartz AG, Zhang ZF, Le Marchand L, Cote ML, Stoddard SM, et al. Tobacco smoking as a risk factor of bronchioloalveolar carcinoma of the lung: pooled analysis of seven case-control studies in the international lung Cancer consortium (ILCCO). Cancer Causes Control. 2011:22:73-9.

2. Lowenfels AB, Maisonneuve P, Whitcomb DC, Lerch MM, DiMagno EP. Cigarette smoking as a risk factor for pancreatic cancer in patients with hereditary pancreatitis. JAMA. 2001;286:169-70.

3. Abdel-Rahman O, Helbling D, Schob O, Eltobgy M, Mohamed H, Schmidt J, Giryes A, Mehrabi A, lype $\mathrm{S}$, John H, et al. Cigarette smoking as a risk factor for the development of and mortality from hepatocellular carcinoma: an updated systematic review of 81 epidemiological studies. J Evid Based Med. 2017; 10:245-54

4. Erhardt L. Cigarette smoking: an undertreated risk factor for cardiovascular disease. Atherosclerosis. 2009;205:23-32.

5. World health Organization WHO report on the global tobacco epidemic 2015 Raising taxes on tobacco http://apps.who.int/iris/bitstream/10665/ 178574/1/9789240694606_eng.pdf?ua=1\&ua=1. Accesses 12 Jan 2018.

6. The Ministry of Health Labour and Welfare. National Health and Nutrition Survey http://www.mhlw.go.jp/file/04-Houdouhappyou-10904750Kenkoukyoku-Gantaisakukenkouzoushinka/kekkagaiyou_7.pdf. Accessed 12 Jan 2018.

7. Centers for Disease Control and Prevention. Currentcigarette smoking among adults_-United States, 2005-2014. https://ac.els-cdn.com/ S037687161730008X/dx.doi.org/10.15585/mmwr.mm6444a2. Accessed 12 Jan 2018.

8. Ojima M, Hanioka T, Tanaka H. Necessity and readiness for smoking cessation intervention in dental clinics in Japan. J Epidemiol. 2012;22:57-63.

9. Kaneita $Y$, Uchida T, Ohida T. Epidemiological study of smoking among Japanese physicians. Prev Med. 2010;51:164-7.

10. Smith DR, Wada K. Declining rates of tobacco use in the Japanese medical. Profession, 1965-2009. J Epidemiol. 2013:23:4-11.

11. Elani HW, Bedos C, Allison PJ. Sources of stress in Canadian dental students: a prospective mixed methods study. J Dent Educ. 2013;77:1488-97.

12. Harris RC, Millichamp CJ, Thomson WM. Stress and coping in fourth-year medical and dental students. N Z Dent J. 2015;111:102-8.

13. Mansour AY. Predictors of smoking among Saudi dental students in Jeddah. Am J Health Behav. 2017:41:329-37.

14. Salin-Pascual RJ, Rosas M, Jimenez-Genchi A, Rivera-Meza BL, Delgado-Parra $\checkmark$. Antidepressant effect of transdermal nicotine patches in nonsmoking patients with major depression. J Clin Psychiatry. 1996;57:387-9.

15. Semba J, Mataki C, Yamada S, Nankai M, Toru M. Antidepressantlike effects of chronic nicotine on learned helplessness paradigm in rats. Biol Psychiatry. 1998:43:389-91

16. Tamaki T, Kaneita Y, Ohida T, Yokoyama E, Osaki Y, Kanda H, Takemura S, Hayashi K. Prevalence of and factors associated with smoking among Japanese medical students. J Epidemiol. 2010;20:339-45.

17. Doi Y, Minowa M. Factor structure of the 12-item general health questionnaire in the Japanese general adult population. Psychiatry Clin Neurosci. 2003;57:379-83.
18. Kaneita Y, Ohida T, Osaki Y, Tanihata T, Minowa M, Suzuki K, Wada K, Kanda $\mathrm{H}$, Hayashi K. Association between mental health status and sleep status among adolescents in Japan: a nationwide cross-sectional survey. J Clin Psychiatry. 2007;68:1426-35.

19. Goldberg DP. The detection of psychiatric illness by questionnaire: a technique for the identification and assessment of non-psychotic psychiatric illness. London: Oxford University Press; 1972.

20. Guthrie EA, Black D, Shaw CM, Hamilton J, Creed FH, Tomenson B. Embarking upon a medical career: psychological morbidity in first year medical students. Med Educ. 1995;29:337-41.

21. Ichikawa M, Fujita Y, Hamaguchi A, Chaweewannakorn W, Maki K. Association of tongue pressure with masticatory performance and dental conditions in Japanese children. Ped Dent J. 2016:26:51-9.

22. Kaiser HF. A second-generation little jiffy. Psychometrika. 1970;35:401-15.

23. Kaiser HF, Little Jiffy RJ. Mark IV. Educ Psychol Meas. 1974;34:111-7.

24. Bartlett MS. Tests of significance in factor analysis. Br J Stat Psychol. 1950;3: 77-85.

25. Hu LT, Bentler PM. Cutoff criteria for fit indexes in covariance structure analysis: conventional criteria versus new alternatives. Struct Equ Modeling. 1999;6:1-55

26. Jöreskog KG, Sörbom D. Recent developments in structural equation modeling. J Mark Res. 1982;19:404-16.

27. MacCallum RC, Browne MW, Sugawara HM. Power analysis and determination of sample size for covariance structure modeling. Psychol Methods. 1996;1:130-49.

28. Cronbach $\amalg$, Warrington WG. Time-limit tests: estimating their reliability and degree of speeding. Psychometrika. 1951;16:167-88.

29. AlSwuailem AS, AlShehri MK, Al-Sadhan S. Smoking among dental students at King Saud University: consumption patterns and risk factors. Saudi Dent J. 2014:26:88-95.

30. Tami-Maury I, Silva-Vetri MG, Marcano-Caldera M, Baasch A, Prokhorov AV. Smoking behavior among third year dental students in Latin American countries: prevalence, perceptions, and risk factors. Salud Publica Mex. 2017; 59(Suppl 1):45-53.

31. Fotedar S, Sogi GM, Fotedar V, Bhushan B, Singh B, Dahiya P, Thakur AS Knowledge of, attitude towards, and prevalence of tobacco use among dental students in Himachal Pradesh state. India Oral Health Dent Manag. 2013;12:73-9.

32. Khami MR, Murtomaa H, Razeghi S, Virtanen Jl. Smoking and its determinants among Iranian dental students. Med Princ Pract. 2010; 19:390-4

33. Maatouk F, Barkallah M, May W. Smoking among dental students in Monastir, Tunisia. East Mediterr Health J. 2014;19(Suppl 3):S32-7.

34. Alomari Q, Barrieshi-Nusair K, Said K. Smoking prevalence and its effect on dental health attitudes and behavior among dental students. Med Princ Pract. 2006;15:195-9.

35. Rahman B, Hawas N, Rahman MM. Opinions of dental students toward tobacco cessation intervention in the United Arab Emirates. Int Dent J. 2016;66:304-10.

36. Miyazaki Y, Hayashi K, Mizunuma H, Lee JS, Katanoda K, Imazeki S, Suzuki S. Smoking habits in relation to reproductive events among Japanese women: findings of the Japanese Nurses' health study. Prev Med. 2013;57:729-31.

37. Anderka M, Romitti PA, Sun L, Druschel C, Carmichael S, Shaw G. Patterns of tobacco exposure before and during pregnancy. Acta Obstet Gynecol Scand. 2010:89:505-14

38. Levinson AH, Campo S, Gascoigne J, Jolly O, Zakharyan A, Tran ZV. Smoking, but not smokers: identity among college students who smoke cigarettes. Nicotine Tob Res. 2007;9:845-52.

39. Eticha T, Kidane F. The prevalence of and factors associated with current smoking among College of Health Sciences students, Mekelle University in northern Ethiopia. PLoS One. 2014;9:e111033.

40. Mckee SA, Hinson R, Rounsaville D, Petrelli P. Survey of subjective effects of smoking while drinking among college students. Nicotine Tob Res. 2004:6:111-7.

41. Brady KT, Sonne SC. The role of stress in alcohol use, alcoholism treatment, and relapse. Alcohol Res Health. 1999;23:263-71.

42. Pohorecky LA. Interaction of ethanol and stress: research with experimental animals--an update. Alcohol Alcohol. 1990:25:263-76.

43. Chester JA, Blose AM, Zweifel M, Froehlich JC. Effects of stress on alcohol consumption in rats selectively bred for high or low alcohol drinking. Alcohol Clin Exp Res. 2004;28:385-93. 
44. Rosenquist JN, Murabito J, Fowler JH, Christakis NA. The spread of alcohol consumption behavior in a large social network. Ann Intern Med. 2010;152: 426-33 W141.

45. Christakis NA, Fowler $\mathrm{JH}$. The collective dynamics of smoking in a large social network. N Engl J Med. 2008;358:2249-58.

46. King JL, Reboussin BA, Spangler J, Cornacchione Ross J, Sutfin EL. Tobacco product use and mental health status among young adults. Addict Behav. 2018;77:67-72

47. Primack BA, Land SR, Fan J, Kim KH, Rosen D. Associations of mental health problems with waterpipe tobacco and cigarette smoking among college students. Subst Use Misuse. 2013:48:211-9.

48. Ohtsu T, Kaneita Y, Osaki Y, Kokaze A, Ochiai H, Shirasawa T, Nanri H, Ohida T. Mental health status among Japanese medical students: a cross-sectional survey of 20 universities. Acta Med Okayama. 2014;68:331-7.

49. Phan KL, Fitzgerald DA, Nathan PJ, Moore GJ, Uhde TW, Tancer ME. Neural substrates for voluntary suppression of negative affect: a functional magnetic resonance imaging study. Biol Psychiatry. 2005:57:210-9.

50. Horne JA, Ostberg O. A self-assessment questionnaire to determine morningness-eveningness in human circadian rhythms. Int J Chronobiol. 1976:4:97-110

51. Wittmann M, Dinich J, Merrow M, Roenneberg T. Social jetlag: misalignment of biological and social time. Chronobiol Int. 2006;23:497-509.

52. Meule A, Roeser K, Randler C, Kubler A. Skipping breakfast: morningnesseveningness preference is differentially related to state and trait food cravings. Eat Weight Disord. 2012;17:e304-8.

53. Pabst SR, Negriff S, Dorn LD, Susman EJ, Huang B. Depression and anxiety in adolescent females: the impact of sleep preference and body mass index. J Adolesc Health. 2009:44:554-60.

54. Hidalgo MP, Caumo W, Posser M, Coccaro SB, Camozzato AL, Chaves ML. Relationship between depressive mood and chronotype in healthy subjects. Psychiatry Clin Neurosci. 2009;63:283-90.

55. Patterson F, Malone SK, Lozano A, Grandner MA, Hanlon AL. Smoking, screen-based sedentary behavior, and diet associated with habitual sleep duration and Chronotype: data from the UK biobank. Ann Behav Med. 2016; 50:715-26.

56. Agaku IT, Ayo-Yusuf OA, Connolly GN. Tobacco cessation training among dental and other health professions students in eight low- and middleincome countries. J Dent Educ. 2014;78:75-84.

57. Prakash P, Belek MG, Grimes B, Silverstein S, Meckstroth R, Heckman B, Weintraub JA, Gansky SA, Walsh MM. Dentists' attitudes, behaviors, and barriers related to tobacco-use cessation in the dental setting. J Public Health Dent. 2013;73:94-102.

58. Pendharkar B, Levy SM, McQuistan MR, Qian F, Squier CA, Slach NA, Aquilino ML. Fourth-year dental students' perceived barriers to providing tobacco intervention services. J Dent Educ. 2010;74:1074-85.

59. Davis JM, Ramseier CA, Mattheos N, Schoonheim-Klein M, Compton S, AlHazmi N, Polychronopoulou A, Suvan J, Antohe ME, Forna D, Radley N. Education of tobacco use prevention and cessation for dental professionals--a paradigm shift. Int Dent J. 2010;60:60-72.

60. Singleton JA, Carrico RM, Myers JA, Scott DA, Wilson RW, Worth CT. Tobacco cessation treatment education for dental students using standardized patients. J Dent Educ. 2014;78:895-905.

\section{Ready to submit your research? Choose BMC and benefit from:}

- fast, convenient online submission

- thorough peer review by experienced researchers in your field

- rapid publication on acceptance

- support for research data, including large and complex data types

- gold Open Access which fosters wider collaboration and increased citations

- maximum visibility for your research: over $100 \mathrm{M}$ website views per year

At $\mathrm{BMC}$, research is always in progress.

Learn more biomedcentral.com/submissions 